\title{
THE FRANKLIN INSTITUTE
}

(Proceedings of the Stated Meeting held Wednesday, November 15, 19r6.)

Hall of the Franklin Institute,

Philadelphia, November 15, 1916.

President Dr. Walton Clark in the Chair.

Additions to membership since last report, 9 .

The paper of the evening was presented by Jacques Loeb, M.D., D.Sc., Ph.D., Head of Department of Experimental Biology, Rockefeller Institute, New York, on "The Production of Normal Animals from Unfertilized Eggs by Physico-Chemical Means."

The speaker described the means by which normal larva can be produced from unfertilized eggs of marine animals and called attention to the conclusions which can be drawn from these experiments concerning the mechanism of natural fertilization. The production of normal frogs from unfertilized eggs was next considered as well as the question of their sex. A full explanation of the various stages of fertilization and development was also given.

The subject was illustrated by diagrams, lantern slides and specimens of frogs produced from unfertilized eggs.

After a vote of thanks to the speaker the meeting adjourned.

R. B. OWENS, Secretary.

\section{COMMITTEE ON SCIENCE AND THE ARTS.}

(Abstract of Proceedings of the Stated Meeting held Wednesday, November I, 1916.)

Hall of The Franklin Institute, Philadelphia, November I, I9i6.

Mr. C. E. Bontne in the Chair.

The following reports were presented for first reading:

No. 2668.-Linear Hot-Wire Anemometer.

No. 2677.-_" Midget" Marvel Flour Mill.

The following reports were presented for final action:

No. 2675.-Sharples Super-Centrifuge.

Edward Longstreth Medal of Merit to The Sharples Specialty Company, of West Chester, Pa., adopted.

No. 2638.-Herr's Continuous Automatic Centrifugal.

Final action deferred.

No. 2658.-Copes Boiler Feed Regulator. Advisory.

R. B. OwEN, Secretary.

VoL. I 82, No. $1092-56$ $8 \mathrm{I} 3$ 